\title{
Spontaneous Electronic Cigarette Explosion: A Case Report
}

\author{
Lee M Jablow*', Ryan J Sexton \\ Department of Emergency Medicine, Cooper University Hospital, Kelemen 152, Camden, NJ 08103 \\ *Corresponding author: jablow-lee@cooperhealth.edu \\ Received February 06, 2015; Revised February 12, 2015; Accepted February 26, 2015
}

\begin{abstract}
The electronic cigarette (e-cigarette) industry is rapidly growing and safety dataregarding e-cigarette use are limited. We present the case of a 30-year-old man who sustained partial thickness burns to his right leg following the spontaneous ignition of an e-cigarette battery that was being stored in his pants pocket. As the e-cigarette industry continues to rapidly grow, we must be aware of this potential danger.
\end{abstract}

Keywords: burns, electronic cigarette, e-cigarette, spontaneous ignition, lithium battery

Cite This Article: Lee M Jablow, and Ryan J Sexton, "Spontaneous Electronic Cigarette Explosion: A Case Report.” American Journal of Medical Case Reports, vol. 3, no. 4 (2015): 93-94. doi: 10.12691/ajmcr-3-4-1.

\section{Introduction}

Cigarette smoking is the leading preventable cause of death in the United States [1]. Smoking is responsible for $80 \%$ of deaths from COPD [2], increases the risk for coronary artery disease and stroke by 2-4 times [2], and increases the risk of lung cancer by 25 times [2]. It is therefore not surprising that electronic cigarettes (ecigarettes) are gaining popularity as a potentially safer alternative to traditional cigarette smoking. As of early 2014, there were 466 brands and 7764 unique flavors of ecigarette products, with an estimated market that could total \$5 billion next year [3]. Recently, the American Heart Association (AHA) released a policy statement that physicians should not discourage the use of e-cigarettes by patients attempting to quit smoking [3]. However, neither the long-term safety profile nor the incidence of acute injury from device malfunction due to e-cigarette use have been well established.

\section{Case Report}

We report the case of a 30-year-old man who sustained partial thickness burns to his right leg and circumferentially to his right knee after the battery of an ecigarette ignited in his pants pocket. While attending a rock music concert, the man reported hearing a sudden loud noise described as an "explosion" which caused his entire right pants leg to rapidly ignite in flames. He was not using the device at the time of its ignition, and denied misuse of the product. There was no nearby alternative source of heat or chemical exposure at the time of the explosion. The patient was unaware of the manufacturer or model type of his e-cigarette device. He was able to quickly extinguish the flames and immediately requested emergency medical attention from event staff, whereby he was transported by EMS to the nearest Emergency Department along with the exploded e-cigarette cartridge (Figure 1).

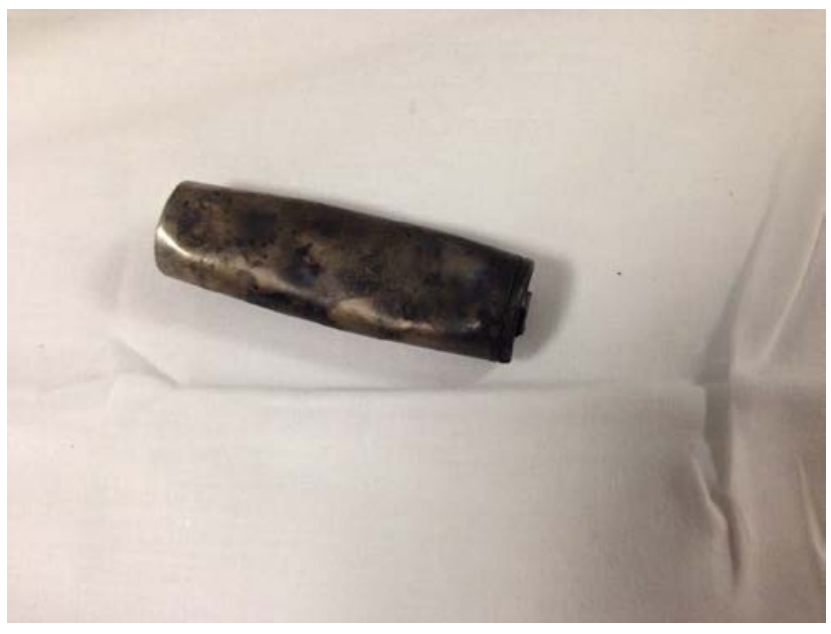

Figure 1. The electronic cigarette cartridge brought in by EMS after the explosion

The patient presented to our Emergency Department complaining of severe pain in the burned right lower extremity. On assessment, his vital signs were within normal limits and his airway was unaffected. He was found to have a superficial partial-thickness burn to the lateral aspect of his right leg, which extended to the medial aspect of the leg, with approximately 8\% total body surface area involvement. Gentle cleaning with water-soaked gauze (Figure 2) revealed extensive blistering to the lateral leg, with intact sensation throughout the burned region. The patient sustained no trauma other than the described burns to his right lower extremity. He was neurovascularly intact distal to the injury and there was no indication for emergent escharotomy. He required multiple doses of intravenous opioid analgesia, his burn wounds were irrigated, covered 
with dry sterile dressing, and he was transferred to the closest appropriate burn center in accordance with the American Burn Association Referral Criteria [4].

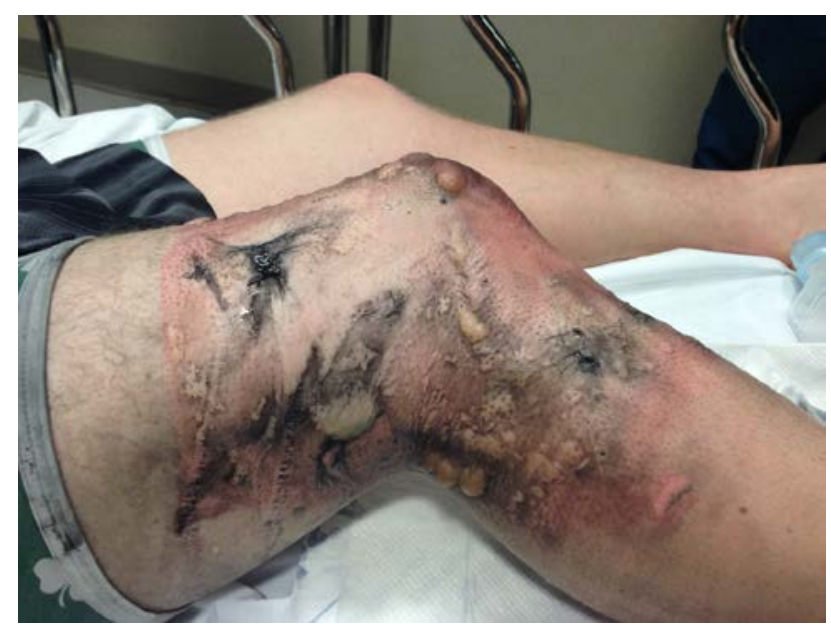

Figure 2. The patient's burned right lower extremity after gentle cleaning of the wound with water-soaked gauze 10 minutes after ED arrival

\section{Discussion}

E-cigarettes, which lack the tobacco and carcinogenic compounds of traditional cigarettes, are battery-operated and fall within the general category of vaporizer products [3]. These devices include cartridges or refillable tanks containing a liquid mixture composed primarily of nicotine, flavoring, water, glycerin, and propylene glycol [5]. By a unique mechanical design, these chemicals are inhaled via a mouthpiece and exhaled as a fine mist [5]. To date, relatively little research has been conducted on the health effects of e-cigarettes, with mostly minor side effects of mouth irritation, dry cough, nausea and vomiting reported with little or no evidence of serious adverse events [3].

Many e-cigarettes use lithium batteries due to their ability to store large amounts of energy in a compact amount of space [2]. However, the inherent characteristics of lithium batteries can pose a risk of fire and explosion. Partial thickness burns caused by spontaneously exploding mobile phones has been described in the literature [6]. The lithium ion battery has separately been described as the "mini bomb in your pocket," due to its known ability to spontaneously ignite [7]. Poor design, use of low-quality materials, manufacturing flaws and defects, and improper use and handling can all contribute to a condition known as 'thermal runway,' whereby the internal battery temperature can increase to the point of causing a battery fire or explosion [5].

While evidence of e-cigarette use on long-term overall health is limited, we describe the first case of an acute injury requiring advanced medical attention due to malfunction of an e-cigarette device. Awareness of the potential for serious burn injuries associated with ecigarette use is important from a public health standpoint. As the e-cigarette industry continues to grow, the potential for serious burn injuries related to device malfunction is of concern.

\section{Financial Support}

This research received no specific grant from any funding agency, commercial or not-for-profit sectors.

\section{Conflicts of Interest}

None.

IRB approval was not required or obtained

\section{Acknowledgements}

The authors wish to acknowledge Dr. Steven E Ross, MD for his assistance with the initial literature search and Dr. Christopher $\mathrm{W}$ Jones, $\mathrm{MD}$ for reviewing the manuscript.

\section{References}

[1] Centers for Disease Control and Prevention: Health Effects of Cigarette Smoking.

http://www.cdc.gov/tobacco/data_statistics/fact_sheets/health_effe cts/effects_cig_smoking/. Last accessed 09/03/2014.

[2] U.S. Department of Health and Human Services. The Health Consequences of Smoking - 50 Years of Progress: A Report of the Surgeon General. Atlanta: U.S. Department of Health and Human Services, Centers for Disease Control and Prevention, National Center for Chronic Disease Prevention and Health Promotion, Office on Smoking and Health, 2014. Last accessed 08/25/2014.

[3] Bhatnagar A, Whitsel LP, Ribisl KM, et al; on behalf of the American Heart Association Advocacy Coordinating Committee, Council on Cardiovascular and Stroke Nursing, Council on Clinical Cardiology, and Council on Quality of Care and Outcomes Research. Electronic cigarettes: A policy statement from the American Heart Association. Circulation 2014: 1-15.

[4] American Burn Association Referral Criteria. http://www.ameriburn.org/BurnCenterReferralCriteria.pdf. Last accessed 08/25/2014.

[5] Brown CM, Cheng JM. Electronic cigarettes: product characterisation and design considerations Tob Control 2014;23:ii4-ii10.

[6] Karabagli Y, Kose, AA, Cetin C. Partial thickness burns caused by a spontaneously exploding mobile phone. Burns 2006 Nov; 32(7):922-4.

[7] Ben D, Ma B, Liu L, et al. Unusual burns with combined injuries caused by mobile phone explosion: watch out for the "mini-bomb"! J Burn Care Res 2009 Nov-Dec; 30(6):1048. 